Neurotoxicology. 2013 December ; 39: . doi:10.1016/j.neuro.2013.09.005.

\title{
Brain Levels of the Neurotoxic Pyridinium Metabolite HPP+ and Extrapyramidal Symptoms in Haloperidol-Treated Mice
}

\author{
James J. Crowley ${ }^{1}$, Mehdi Ashraf-Khorassani ${ }^{2}$, Neal Castagnoli $\mathrm{Jr}^{2}$, and Patrick F. \\ Sullivan ${ }^{1,3}$ \\ ${ }^{1}$ Center for Psychiatric Genomics, Department of Genetics; University of North Carolina at Chapel \\ Hill, NC, USA \\ ${ }^{2}$ Department of Chemistry, Virginia Polytechnic Institute and State University, Blacksburg, VA, \\ USA \\ ${ }^{3}$ Department of Psychiatry; University of North Carolina at Chapel Hill, NC, USA
}

\begin{abstract}
The typical antipsychotic haloperidol is a highly effective treatment for schizophrenia but its use is limited by a number of serious, and often irreversible, motor side effects. These adverse drug reactions, termed extrapyramidal syndromes (EPS), result from an unknown pathophysiological mechanism. One theory relates to the observation that the haloperidol metabolite HPP+ (4-(4chlorophenyl)-1-[4-(4-fluorophenyl)-4-oxobutyl]-pyridinium) is structurally similar to MPP+ (1methyl-4-phenylpyridinium), a neurotoxin responsible for an irreversible neurodegenerative condition similar to Parkinson's disease. To determine whether HPP+ contributes to haloperidolinduced EPS, we measured brain HPP+ and haloperidol levels in strains of mice at high (C57BL/ $6 \mathrm{~J}$ and NZO/HILtJ) and low (BALB/cByJ and PWK/PhJ) liability to haloperidol-induced EPS following chronic treatment (7-10 adult male mice per strain). Brain levels of HPP+ and the ratio of HPP+ to haloperidol were not significantly different between the haloperidol-sensitive and haloperidol-resistant strain groups $(\mathrm{P}=0.50)$. Within each group, however, strain differences were seen $(\mathrm{P}<0.01)$, indicating that genetic variation regulating steady-state HPP+ levels exists. Since the HPP+ levels that we observed in mouse brain overlap the range of those detected in postmortem human brains following chronic haloperidol treatment, the findings from this study are physiologically relevant to humans. The results suggest that strain differences in steady-state HPP + levels do not explain sensitivity to haloperidol-induced EPS in the mice we studied.
\end{abstract}

\section{Keywords}

haloperidol; adverse drug reaction; tardive dyskinesia; mouse; HPTP; HPP+

\footnotetext{
(c) 2013 Elsevier B.V. All rights reserved.

Correspond with Dr. Crowley: Department of Genetics, CB\#7264, Genetic Medicine Building, University of North Carolina, Chapel Hill, NC, 27599-7264, USA. Voice: +919-966-9576, FAX: +919-966-3630, crowley@unc.edu.

Publisher's Disclaimer: This is a PDF file of an unedited manuscript that has been accepted for publication. As a service to our customers we are providing this early version of the manuscript. The manuscript will undergo copyediting, typesetting, and review of the resulting proof before it is published in its final citable form. Please note that during the production process errors may be discovered which could affect the content, and all legal disclaimers that apply to the journal pertain.

Conflict of Interest Statement

The authors have no financial interests or potential conflicts of interest to declare.
} 


\section{Introduction}

First-generation or "typical" antipsychotic drugs are widely used to treat psychotic disorders, but their use is limited by their propensity to cause a number of motor side effects, collectively termed extrapyramidal syndromes (EPS) (Dayalu \& Chou 2008, Hsin-tung E and Simpson 2000). After acute treatment, about half of patients experience restlessness, involuntary spasms or muscular rigidity (Leucht et al. 2003). With long-term treatment, tardive dyskinesia (TD) develops in about a third of patients (Gerlach \& Casey 1988). TD involves repetitive, involuntary and purposeless movements, primarily of the orofacial region (e.g., chewing movements and tongue protrusion) (Crane 1968). TD is often irreversible (Soares-Weiser \& Fernandez 2007) and there is currently no proven treatment (Tandon et al. 2008). Though a number of theories have been proposed, the precise pathophysiological mechanisms responsible for the development of these adverse drug reactions are not known.

Haloperidol is a prototypical first-generation antipsychotic and is still widely used, despite high liability for EPS. One current theory for the pathophysiological effects of haloperidol relates to its structural similarity with MPTP (1-methyl-4-phenyl-1,2,3,6tetrahydropyridine), a neurotoxic contaminant produced during the manufacture of the synthetic opioid MPPP (1-methyl-4-phenyl-4-propionoxypiperidine). MPTP is responsible for an irreversible neurodegenerative condition similar to Parkinson's disease (Burkhardt $e t$ al. 1993), via its pyridinium metabolite MPP+ (1-methyl-4-phenylpyridinium) (JacksonLewis \& Przedborski 2007). Haloperidol undergoes biotransformation into HPTP (4-(4chlorophenyl)-1-[4-(4-fluorophenyl)-4-oxobutyl]-1,2,3,6-tetrahydropyridine), which is similar in structure to MPTP. Both haloperidol and HPTP can then be oxidized to a pyridinium metabolite HPP+ (the 4-(4-chlorophenyl)-1-[4-(4-fluorophenyl)-4oxobutyl]pyridinium species) which is similar in structure and toxicity to MPP+ (Subramanyam et al. 1990, Rollema et al. 1994, Igarashi et al. 1996, Bloomquist et al. 1994, Fang et al. 1995).

Therefore, it is plausible that HPP+ contributes to the pathophysiological effects of haloperidol via toxicity similar to that of MPP+. Consistent with this notion, HPP+ is found in post-mortem brain tissue, plasma and urine from patients with schizophrenia chronically treated with haloperidol (Eyles et al. 1994, Eyles et al. 1997, Avent et al. 1997, Subramanyam et al. 1991).

A positive relationship between the severity of TD and peripheral blood levels of HPP+ has been reported by two studies of a total of 51 haloperidol-treated patients (Iwahashi et al. 2001, Ulrich et al. 2005). In light of evidence that HPP+ is capable of crossing the bloodbrain barrier (owing to its high lipophilicity) (Kawashima et al. 2002), it is conceivable that peripherally-derived HPP+ (e.g. from the liver) could be taken up by the brain and induce damage. Alternatively, HPP+ could be produced locally in the brain via a currently unidentified enzymatic mechanism. Regardless of its source, however, HPP+ would need to act in the brain to produce haloperidol-induced motor side effects. Since a large, wellcontrolled examination of brain HPP+ levels in subjects with and without TD is infeasible, we have investigated this question using a mouse model where we could tightly control drug exposure, environmental factors and collect brain tissue.

Mice chronically treated with haloperidol demonstrate, in a strain-specific manner, many of the motor side effects seen in humans, including vacuous chewing movements (akin to TD), reduced locomotion (hypokinesia) and muscular rigidity (Parkinsonism) (Fujiwara 1992, Waddington et al. 1983, Ethier et al. 2004). In recent studies we examined susceptibility to haloperidol-induced motor side effects across a panel of 27 inbred mouse strains, finding 
that broad-sense heritability for each of these responses exceeded 70\% (Crowley et al. 2010), and mapped quantitative trait loci regulating drug response (Crowley et al. 2011). To examine whether brain HPP+ levels correlate with EPS susceptibility, we chose two strains that were very sensitive to haloperidol-induced motor side effects (C57BL/6J and NZO/ HILtJ) and two resistant strains (BALB/cByJ and PWK/PhJ) from Crowley et al (Crowley et al. 2010). As shown in Figure 1A, a summary of previously published data (Crowley et al. 2010), following chronic treatment with haloperidol (administered via a slow release implant), C57BL/6J and NZO/HILtJ mice show significantly more tardive-dyskinesia-like chewing movements, hypokinesia and Parkinsonism than BALB/cByJ or PWK/PhJ mice (all $\mathrm{P}<0.01)$. In the present study, we chronically treated $7-10$ adult male mice from each of these strains with haloperidol and measured brain levels of HPP+ and haloperidol.

\section{Methods}

\subsection{Animals}

All testing procedures were conducted in strict compliance with the Guide for the Care and Use of Laboratory Animals and approved by the Institutional Animal Care and Use Committee of the University of North Carolina. Male mice from 4 inbred strains were obtained from the Jackson Laboratory (Bar Harbor, ME). These included two strains previously shown (Crowley et al. 2010) to be highly susceptible to haloperidol-induced vacuous chewing movements (C57BL/6J, N=9, and NZO/HILtJ, N=10) and two strains shown to be largely resistant (BALB/cByJ, $\mathrm{N}=7$, and $\mathrm{PWK} / \mathrm{PhJ}, \mathrm{N}=8$ ).

\subsection{Antipsychotic exposure}

Slow release haloperidol pellets $(6.7 \mathrm{mg} / \mathrm{kg} /$ day; Innovative Research of America; Sarasota, FL) (Fleischmann et al. 2002) were implanted subcutaneously with a trocar under two minutes of isoflurane anesthesia. This method was previously shown to yield human-like steady-state concentrations of haloperidol (4-20 ng/ml) (Hsin-tung E and Simpson 2000) in $>95 \%$ of mice tested across diverse inbred strains (Crowley et al. 2010), including those examined in this study. Pellets were implanted at 8 weeks of age and mice were sacrificed 30 days later.

\subsection{HPP+ and haloperidol levels}

Upon sacrifice, whole brain was collected, weighed, snap frozen in liquid nitrogen and stored at $-80^{\circ} \mathrm{C}$ until analysis. Brains were homogenized with $2 \mathrm{~mL}$ of $1.15 \% \mathrm{KCl}$ solution and an internal standard PB226.3 (oxalate salt of 1,2,5-trimethyl-3-(1-methyl-1,2,3,6tetrahydropyridin-4-yl)-1H-indole) (P. Bissel and N. Castagnoli, Jr., manuscript in preparation) was added to a concentration of $80 \mathrm{ng} / \mathrm{mL}$. For each sample, $0.25 \mathrm{~mL}$ of this solution was mixed with $0.5 \mathrm{~mL}$ of methanol followed by 30 seconds of vortex and centrifugation at $10,000 \mathrm{rpm}$ for $10 \mathrm{~min}$. The supernatant was diluted with $1 \mathrm{~mL}$ of $30 \mathrm{mM}$ $\mathrm{NH}_{4} \mathrm{OAc}$ followed by clean-up through a solid phase extraction cartridge (Igarashi \& Castagnoli 1992). Finally, the eluent was dried under a stream of nitrogen and the residue was re-dissolved in 0.5 or $1 \mathrm{~mL}$ of $70 / 30 \mathrm{H}_{2} \mathrm{O} / \mathrm{MeOH}$ containing $0.2 \%$ acetic acid.

LC/MS/MS with multiple reaction monitoring was then used to measure levels of haloperidol, HPP+ and PB226.3 (Gorrod \& Fang 1993). Standard curves were prepared for both haloperidol (Sigma-Aldrich, St. Louis, MO) and HPP+ (kindly provided by Dr. Kazuo Igarashi). Reversed phase liquid chromatographic separations were performed with an Atlantis C18 $(150 \times 2.1 \mathrm{~mm}, 5.0 \mu \mathrm{m}$ dp) column from Waters (Milford, MA) on an Agilent (Wilmington, DE) 1100 series HPLC equipped with a diode array detector (DAD), column heater set at $40^{\circ} \mathrm{C}$, and Thermo Survey (San Jose, CA) auto sampler. In each analysis, $20 \mu \mathrm{L}$ of standards or sample solution $\left(30 / 70 \mathrm{CH}_{3} \mathrm{OH} / \mathrm{H}_{2} \mathrm{O}\right)$ of each extract was injected onto the 
column via the auto-sampler. Mobile phase A consisted of $1 \%$ formic acid (FA) and mobile phase B contained $1 \%(\mathrm{v} / \mathrm{v}) \mathrm{FA}$ in acetonitrile. The mobile phase was delivered to the HPLC column at a flow rate of $0.2 \mathrm{~mL} / \mathrm{min}$ and the gradient mobile phase elution program was as follows: (time 0 min: 80/20\% A/B; time $6.5 \mathrm{~min}$ : 5/95\% A/B; time $9.5 \mathrm{~min}: 5 / 95 \% \mathrm{~A} / \mathrm{B}$; time 9.6 min: 80/20\% A/B; 14 min: 80/20\% A/B). For MS analysis the HPLC column effluent was pumped directly into a Thermo Instrument TSQ triple quadruple mass spectrometer (Thermo Finnigan, San Jose, CA) equipped with an ESI source. The instrument was calibrated with a solution of polytyrosine according to the manufacture's recommendation. Tuning parameters were obtained by teeing the haloperidol, HPP+ and PB226.3 standards $(10 \mathrm{ng} / \mu \mathrm{L})$ at a rate of $10 \mathrm{uL} / \mathrm{min}$ into $50 / 50 \% \mathrm{~A} / \mathrm{B}$ of mobile phase at a rate of $0.2 \mathrm{~mL} / \mathrm{min}$ to achieve reasonable MS sensitivity in Multiple Reaction Monitoring (MRM). MS parameters for detection were: spray voltage $(4500 \mathrm{~V})$, sheath gas pressure (15 psi), auxiliary gas pressure $(10 \mathrm{psi})$, capillary temperature $\left(300^{\circ} \mathrm{C}\right)$ and polarity (positive). Masses in daltons were: PB226.3 (parent: 255.2, product: 123.0), haloperidol (parent: 376.2, product: 212.0 ) and HPP+ (parent: 354.0, product: 123.0).

\subsection{Statistical analysis}

Brain levels of HPP+ and haloperidol were expressed as ng/gram of wet tissue weight. The effect of strain on levels of HPP+, haloperidol and the ratio of HPP+ to haloperidol was assessed by one-way analysis of variance (ANOVA) followed by pairwise testing using the Tukey-Kramer HSD test using JMP software (version 10.0; SAS; Cary, NC). The statistical analysis results were represented as mean \pm standard error and a $\mathrm{P}<0.05$ was considered statistically significant.

\section{Results and Discussion}

As shown in Figure 1A, following chronic haloperidol treatment, C57BL/6J and NZO/HILtJ mice show significantly more extrapyramidal symptoms than BALB/cByJ or PWK/PhJ mice. The top panel indicates that tardive-dyskinesia-like chewing movements develop most profoundly in C57BL/6J mice, followed by NZO/HILtJ, while BALB/cByJ and PWK/PhJ mice remain largely unaffected. The middle panel demonstrates a clear haloperidol-induced reduction of locomotor activity (hypokinesia) in all four strains, with C57BL/6J and NZO/ HILtJ mice again the most susceptible. The bottom panel shows that NZO/HILtJ mice are most sensitive to haloperidol-induced Parkinsonian-like rigidity on the inclined screen, followed by C57BL/6J and the two resistant strains. To examine whether brain HPP+ levels correlate with EPS susceptibility, we chronically treated adult male mice from these four strains with haloperidol and measured brain levels of HPP+ and haloperidol. Figure 1B displays the structures of compounds relevant to this experiment.

Figure $1 \mathrm{C}$ depicts strain means in the brain concentrations of haloperidol and $\mathrm{HPP}+$. For $\mathrm{HPP}+$, there were significant differences between strains $\left(\mathrm{F}_{3,30}=5.11, \mathrm{P}=0.006\right)$ with $\mathrm{NZO} /$ HILtJ similar to PWK/PhJ and both greater than C57BL/6J and BALB/cByJ. Brain haloperidol concentrations were similar between strains $(\mathrm{P}=0.09)$. The ratio of brain HPP+ to haloperidol was significantly different between strains $(\mathrm{P}=0.002)$ with a pattern of mean differences like that for HPP+ (C57BL/6J: 0.20, NZO/HILtJ: 0.42, BALB/cByJ: 0.14, PWK/ PhJ: 0.40).

We hypothesized that strains with greater EPS would have higher levels of HPP+. As shown in Figure 1C, brain levels of HPP+ and the ratio of HPP+ to haloperidol were not significantly different between the haloperidol-sensitive and haloperidol-resistant strains. Two strains did possess significantly higher levels of HPP+ and a higher ratio of HPP+ to haloperidol (NZO/HILtJ and PWK/PhJ), but this did not match the strain distribution of haloperidol-induced motor side effects. The HPP+ levels that we observed after chronic 
haloperidol treatment (10-60 ng/g of brain tissue) overlap the ranges of those detected in patient brains at post-mortem (Eyles et al. 1997) and in rat brain after acute i.p. injection of $10 \mathrm{mg} / \mathrm{kg}$ (Igarashi \& Castagnoli 1992, Igarashi et al. 1995).

This is the first study to examine brain HPP+ levels in animals at high and low liability to haloperidol-induced EPS. For these four strains, differences in steady-state HPP+ levels do not explain sensitivity to motor side effects. Although our data are not consistent with a simple causal role of HPP+ on EPS in mice, we cannot rule out the possibility that HPP+ is still involved in a more complex manner. For example, it may be possible that a strain like $\mathrm{PWK} / \mathrm{PhJ}$, with relatively high levels of HPP+ and low liability to EPS, is superior at neutralizing the free radical and reactive oxygen species thought to underlie the neurotoxic properties of HPP+. The opposite situation could be true for a strain like C57BL/6J, with relatively low levels of HPP+ and high liability to EPS. These ideas could be tested by administering HPP+ itself to mice from these four strains. Furthermore, previous work has demonstrated important differences in the basal dopaminergic systems of inbred mouse strains. Directly relevant to this study is the observation that the EPS-susceptible strain C57BL/6J has a lower density of dopamine receptors in the caudate nucleus (Sahakian et al. 1980) and lower dopamine content in the hypothalamus than the EPS-resistant strain BALB/ cByJ (George et al. 1995). Further complexity could result from the fact that HPP+ can inhibit the presynaptic uptake of dopamine and serotonin (Wright et al. 1998) and that brain gene expression among inbred strains is known to differ widely (Letwin et al. 2006).

The inclusion of more mouse strains with divergent responses to haloperidol would, of course, provide a more powerful test of the hypothesis examine here. This could be achieved, for example, by sampling more of the 27 strains examined in Crowley et al (Crowley et al. 2010) or by screening other divergent populations such as the Collaborative Cross (Welsh et al. 2012) or Diversity Outbred (Churchill et al. 2012).

It is also conceivable that HPP+ levels vary across different brain regions and by examining whole brain HPP+ levels important differences were diluted out. Data from the literature are limited in this regard, with one human study reporting modest differences across regions (Eyles et al. 1997) and one rat study reporting 7-fold higher levels in the striatum versus whole brain (Igarashi and Castagnoli 1992). The small size of the mouse brain and trace levels of HPP+ forced us to include whole brain tissue in this study.

In conclusion, this study of haloperidol-sensitive and haloperidol-resistant inbred mouse strains failed to support the suggestion that HPP+-induced neurotoxicity contributes to the extrapyramidal side-effects seen in patients receiving long-term typical antipsychotic therapy.

\section{Acknowledgments}

Funding was provided by an NIMH/NHGRI Center of Excellence for Genome Sciences grant (P50 MH090338 and P50 HG006582). This work was also supported by K01 MH094406 (PI Dr. James Crowley).

\section{References}

Avent KM, Riker RR, Fraser GL, Van der Schyf CJ, Usuki E, Pond SM. Metabolism of haloperidol to pyridinium species in patients receiving high doses intravenously: is HPTP an intermediate? Life Sci. 1997; 61:2383-2390. [PubMed: 9399630]

Bloomquist J, King E, Wright A, Mytilineou C, Kimura K, Castagnoli K, Castagnoli N Jr. 1-Methyl-4phenylpyridinium-like neurotoxicity of a pyridinium metabolite derived from haloperidol: cell culture and neurotransmitter uptake studies. J Pharmacol Exp Ther. 1994; 270:822-830. [PubMed: 8071874] 
Burkhardt C, Kelly JP, Lim YH, Filley CM, Parker WD Jr. Neuroleptic medications inhibit complex I of the electron transport chain. Ann Neurol. 1993; 33:512-517. [PubMed: 8098932]

Churchill GA, Gatti DM, Munger SC, Svenson KL. The Diversity Outbred mouse population. Mamm Genome. 2012; 23:713-718. [PubMed: 22892839]

Crane GE. Tardive dyskinesia in patients treated with major neuroleptics: a review of the literature. Am J Psychiatry. 1968; 124(Suppl):40-48. [PubMed: 4865731]

Crowley JJ, Adkins DE, Pratt AL, et al. Antipsychotic-induced vacuous chewing movements and extrapyramidal side effects are highly heritable in mice. The pharmacogenomics journal. 2010

Crowley JJ, Kim Y, Szatkiewicz JP, et al. Genome-wide association mapping of loci for antipsychoticinduced extrapyramidal symptoms in mice. Mammalian genome. 2011 Epub 12/31/2011.

Dayalu P, Chou KL. Antipsychotic-induced extrapyramidal symptoms and their management. Expert Opin Pharmacother. 2008; 9:1451-1462. [PubMed: 18518777]

Ethier I, Kagechika H, Shudo K, Rouillard C, Levesque D. Docosahexaenoic acid reduces haloperidolinduced dyskinesias in mice: involvement of Nur77 and retinoid receptors. Biol Psychiatry. 2004; 56:522-526. [PubMed: 15450789]

Eyles DW, Avent KM, Stedman TJ, Pond SM. Two pyridinium metabolites of haloperidol are present in the brain of patients at post-mortem. Life Sci. 1997; 60:529-534. [PubMed: 9042387]

Eyles DW, McLennan HR, Jones A, McGrath JJ, Stedman TJ, Pond SM. Quantitative analysis of two pyridinium metabolites of haloperidol in patients with schizophrenia. Clin Pharmacol Ther. 1994; 56:512-520. [PubMed: 7955815]

Fang J, Zuo D, Yu PH. Comparison of cytotoxicity of a quaternary pyridinium metabolite of haloperidol (HP+) with neurotoxin N-methyl-4-phenylpyridinium (MPP+) towards cultured dopaminergic neuroblastoma cells. Psychopharmacology (Berl). 1995; 121:373-378. [PubMed: 8584620]

Fleischmann N, Christ G, Sclafani T, Melman A. The effect of ovariectomy and long-term estrogen replacement on bladder structure and function in the rat. J Urol. 2002; 168:1265-1268. [PubMed: 12187279]

Fujiwara H. Comparative studies of sulpiride and classical neuroleptics on induction of catalepsy, locomotor activity, and brain dopamine metabolism in mice. Pharmacol Biochem Behav. 1992; 41:301-308. [PubMed: 1349435]

George SR, Fan T, Ng GY, Jung SY, O'Dowd BF, Naranjo CA. Low endogenous dopamine function in brain predisposes to high alcohol preference and consumption: reversal by increasing synaptic dopamine. J Pharmacol Exp Ther. 1995; 273:373-379. [PubMed: 7714791]

Gerlach J, Casey DE. Tardive dyskinesia. Acta Psychiatr Scand. 1988; 77:369-378. [PubMed: 2898870]

Gorrod JW, Fang J. On the metabolism of haloperidol. Xenobiotica. 1993; 23:495-508. [PubMed: 8342297]

Hsin-tung, E.; Simpson, G. Kaplan and Sadocks's Comprehensive Textbook of Psychiatry. Vol. Vol. 2. Philadelphia: Lippincott, Williams and Wilkins; 2000. Medication-induced movement disorders; p. 2265-2271.

Igarashi K, Castagnoli N Jr. Determination of the pyridinium metabolite derived from haloperidol in brain tissue, plasma and urine by high-performance liquid chromatography with fluorescence detection. J Chromatogr. 1992; 579:277-283. [PubMed: 1429975]

Igarashi K, Kasuya F, Fukui M, Usuki E, Castagnoli N Jr. Studies on the metabolism of haloperidol (HP): the role of CYP3A in the production of the neurotoxic pyridinium metabolite HPP+ found in rat brain following ip administration of HP. Life Sci. 1995; 57:2439-2446. [PubMed: 8847965]

Igarashi K, Matsubara K, Kasuya F, Fukui M, Idzu T, Castagnoli N Jr. Effect of a pyridinium metabolite derived from haloperidol on the activities of striatal tyrosine hydroxylase in freely moving rats. Neurosci Lett. 1996; 214:183-186. [PubMed: 8878114]

Iwahashi K, Anemo K, Nakamura K, Fukunishi I, Igarashi K. Analysis of the metabolism of haloperidol and its neurotoxic pyridinium metabolite in patients with drug-induced parkinsonism. Neuropsychobiology. 2001; 44:126-128. [PubMed: 11586051]

Jackson-Lewis V, Przedborski S. Protocol for the MPTP mouse model of Parkinson's disease. Nat Protoc. 2007; 2:141-151. [PubMed: 17401348] 
Kawashima H, Iida Y, Kitamura Y, Kiyono Y, Magata Y, Saji H. Brain extraction of 4-(4chlorophenyl)-1-[4-(4-fluorophenyl)-4-oxobutyl]pyridinium ion (HPP+), a neurotoxic metabolite of haloperidol: studies using [3H]HPP+ Jpn J Pharmacol. 2002; 89:426-428. [PubMed: 12233823]

Letwin NE, Kafkafi N, Benjamini Y, Mayo C, Frank BC, Luu T, Lee NH, Elmer GI. Combined application of behavior genetics and microarray analysis to identify regional expression themes and gene-behavior associations. J Neurosci. 2006; 26:5277-5287. [PubMed: 16707780]

Leucht S, Wahlbeck K, Hamann J, Kissling W. New generation antipsychotics versus low-potency conventional antipsychotics: a systematic review and meta-analysis. Lancet. 2003; 361:15811589. [PubMed: 12747876]

Rollema H, Skolnik M, D'Engelbronner J, Igarashi K, Usuki E, Castagnoli N Jr. MPP(+)-like neurotoxicity of a pyridinium metabolite derived from haloperidol: in vivo microdialysis and in vitro mitochondrial studies. J Pharmacol Exp Ther. 1994; 268:380-387. [PubMed: 8301579]

Sahakian BJ, Carlson KR, DeGirolami U, Bhawan J. Functional and structural consequences of longterm dietary L-dopa treatment in mice. Commun Psychopharmacol. 1980; 4:169-176. [PubMed: 7428338]

Soares-Weiser K, Fernandez HH. Tardive dyskinesia. Semin Neurol. 2007; 27:159-169. [PubMed: 17390261]

Subramanyam B, Pond SM, Eyles DW, Whiteford HA, Fouda HG, Castagnoli N Jr. Identification of potentially neurotoxic pyridinium metabolite in the urine of schizophrenic patients treated with haloperidol. Biochem Biophys Res Commun. 1991; 181:573-578. [PubMed: 1755839]

Subramanyam B, Rollema H, Woolf T, Castagnoli N Jr. Identification of a potentially neurotoxic pyridinium metabolite of haloperidol in rats. Biochem Biophys Res Commun. 1990; 166:238-244. [PubMed: 2302206]

Tandon R, Belmaker RH, Gattaz WF, et al. World Psychiatric Association Pharmacopsychiatry Section statement on comparative effectiveness of antipsychotics in the treatment of schizophrenia. Schizophr Res. 2008; 100:20-38. [PubMed: 18243663]

Ulrich S, Sandmann U, Genz A. Serum concentrations of haloperidol pyridinium metabolites and the relationship with tardive dyskinesia and parkinsonism: a cross-section study in psychiatric patients. Pharmacopsychiatry. 2005; 38:171-177. [PubMed: 16025420]

Waddington JL, Cross AJ, Gamble SJ, Bourne RC. Spontaneous orofacial dyskinesia and dopaminergic function in rats after 6 months of neuroleptic treatment. Science. 1983; 220:530532. [PubMed: 6132447]

Welsh CE, Miller DR, Manly KF, et al. Status and access to the Collaborative Cross population. Mamm Genome. 2012; 23:706-712. [PubMed: 22847377]

Wright AM, Bempong J, Kirby ML, Barlow RL, Bloomquist JR. Effects of haloperidol metabolites on neurotransmitter uptake and release: possible role in neurotoxicity and tardive dyskinesia. Brain Res. 1998; 788:215-222. [PubMed: 9555021] 


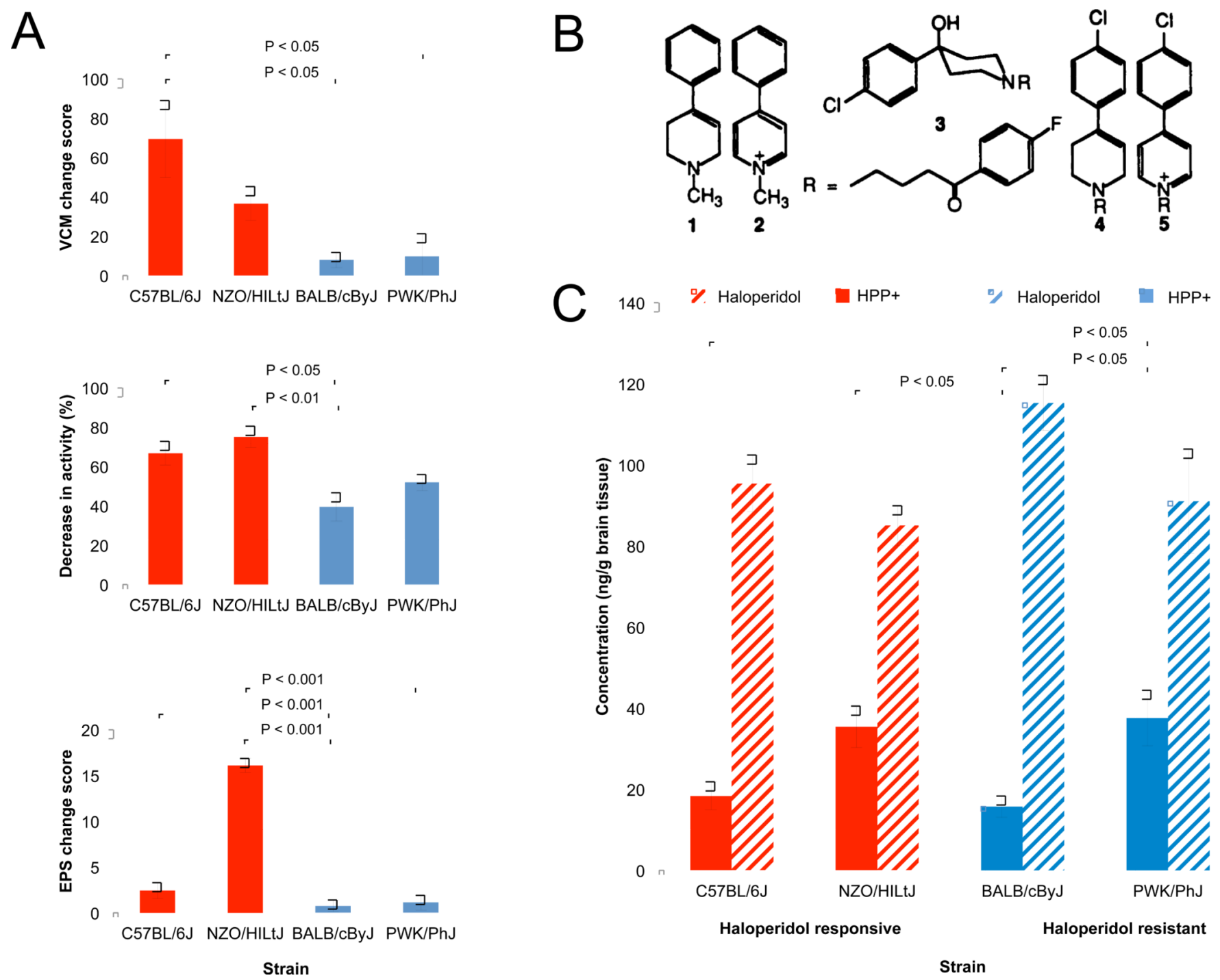

Figure 1.

Haloperidol response and brain HPP+ levels across four inbred mouse strains. A)

Phenotypic data from Crowley et al (Crowley et al. 2010) demonstrating that, after chronic haloperidol treatment, C57BL/6J and NZO/HILtJ mice show more vacuous chewing movements, a greater decrease in locomotor activity and more rigidity than BALB/cByJ or $\mathrm{PWK} / \mathrm{PhJ}$ mice. B) Structures of compounds discussed in the text. 1: 1-methyl-4phenyl-1,2,3,6-tetrahydropyridine (MPTP); 2: 1-methyl-4-phenylpyridinium species (MPP +); 3: haloperidol (HP); 4: haloperidol tetrahydropyridine derivative (HPTP); 5: haloperidol pyridinium species ( $\mathrm{HPP}+)$. C) Brain HPP+ and haloperidol levels across these four strains. Taken together, the haloperidol responsive strains did not differ from the resistant strains in overall HPP+ or haloperidol levels, or the ratio of HPP+ to haloperidol. 